\title{
Addressing the Scientific Challenges of Our Age Begins with Human Connection
}

\author{
Sir Keith Burnett
}

\begin{abstract}
Chinese 'people to people' links as an international strategy are deeply embedded in Chinese culture. Facilitating bonds between countries begins by creating connections between people. This essay describes the compelling need for nations and China to come together for mutual benefit to consider the economic and institutional frameworks that will make this possible. Case studies citing the value of links in science between $U K$ and China are given here, but in this process, high priority must be given to building personal relationships. Personal experiences can demolish so many of the simplistic notions held by non-Chinese people about China. Often outside of China, Chinese stereotypes are mostly drawn from films and photographs of the old China - think Bruce Lee, the land of the bicycle and pastoral images of rice paddies farmed by hand. Through personal relations, visitors to China can discover a developing nation made up of millions of families keen to embrace technology and a better life for their children. China has opened up, and with it has a sense of possibility of trade, exchange and shared scholarship. Yet without a greater comprehension of China, its history and its language, any understanding of the world is incomplete.
\end{abstract}

Keywords Chinese 'people to people' links Chinese culture $\cdot$ Links in science between UK and China $\cdot$ Chinese stereotypes $\cdot$ Greater comprehension of China

As a scientist, my life and work have been marked by international connection and exchange, and my scientific forefathers and teachers reflect a global story. It is one in which China plays a vital role.

I first travelled to China in 2004 as a physicist working at The University of Oxford. I was accompanying the then Vice-Chancellor Sir Colin Lucas and the eminent historian Dame Jessica Rawson, an expert on China's artistic treasures who was securing materials on loan from the Forbidden City for the first major exhibition of these artifacts to be held at the Royal Academy in London.

Yet, it was not just the treasures of ancient China which caught my attention. This was my first experience of a vast nation of 1.4 billion people, and I was simply captivated by this place and the Chinese people I saw and met.

\footnotetext{
K. Burnett $(\bowtie)$

Schmidt Science Fellows, Oxford University, Oxford, UK 
My personal experiences also demolished so many of the simplistic notions I had of China. My stereotypes were mostly drawn from films and photographs of the old China - think Bruce Lee, the land of the bicycle and pastoral images of rice paddies farmed by hand.

Instead, I discovered a developing nation made up of millions of families keen to embrace technology and a better life for their children. China was opening and with it came a sense of possibility for trade, exchange and shared scholarship. Yet, it was clear to me that without a greater comprehension of this astonishing country and its language, my understanding of the world was incomplete.

Through my work, I met both dear Chinese colleagues and students and been deeply impressed by their insights and commitment. Chinese scholarship has too long been underestimated in the West by those ignorant of the dedication of those working across many friends of study, but my own experience showed me this was wrong. The challenges of the future would require a global effort and many brilliant minds were to be found in the great universities of the East. It was equally clear that China would be heavily investing in them and their research to build up the potential of the country to move beyond a low-wage economy to a highly skilled future as an innovative global power. Yet most of all, I was struck by the people I met, and I travelled home to Oxford changed by what I had seen.

I first began to learn Chinese using simple tapes on my Sony Walkman and later on an iPod as I walked between my home and my office as Chairman of Physics in Oxford. I had more Chinese students now and my research group was genuinely international. I also read books and stories and practised writing Chinese characters, my fascination growing along with further opportunities to visit this extraordinary land.

My connection with China later became more personal in a surprising way. My son was studying in London and met a wonderful young woman from Guangzhou who later became his wife. China was no longer just somewhere I visited professionally, we had family there. At my son's Chinese wedding, I met generations of warm and loving people who cared deeply for my daughter-in-law. There was laughter and joy. It was apparent to everyone that the love of our families and fervent hope for their happiness knew no linguistic or geographic bounds.

In 2007, I became a university President, and suddenly, I acquired an even larger Chinese family of several thousand undergraduate and postgraduate students, as well as gifted Chinese colleagues across a host of disciplines. These young people had travelled to the UK from China in search of an excellent education, and it was my sacred duty as a teacher to honour the investment in money, time and love made by their families. I did my very best to do so.

In turn, their investment blessed our adopted city of Sheffield. A stunning new home for Engineering and many other students was built largely thanks to the investment of Chinese families in UK education. Chinese students directly benefitted, as did their British peers and the community around us. The impressive building was opened by the first ever UK astronaut Helen Sharman, a graduate of the university who reminded us of our global connections as common citizens of our remarkable blue planet. Now, China itself has a space programme, and in 2020, it planted its 
flag on the moon, only the second nation to do so. Having visited the Chinese Space Academy in Shanghai, I have no doubt this is just the beginning.

Throughout my time as a University President and Vice-Chancellor, I continued to study Chinese and travelled to China often, visiting scientists in Beijing and Shanghai, and our partners at Nanjing University. There, language became a bridge across which ideas flowed and which allowed friendships to deepen-we shared ideas about the way our work on materials or battery technologies might reduce pollution and a reliance on fossil fuels, and recognised a common need to ensure research that fed into our manufacturing sectors, renewing outdated industries and creating opportunities for the young.

In doing so, we met one another with respect and affection, and realised we had more in common than originally thought. Back in the UK, Chinese language teachers gave their full efforts and commitments to teaching children, students, health workers and business leaders the Chinese languages skills to make connections of their own. I was hopeful that we might indeed be entering a new golden era of cooperation, while recognising the rise of forces of separatism and nationalism which had once again emerged across the world.

I completed my service as a University President in 2018, and shortly thereafter, my son and Chinese daughter-in-law had their own son, Jacob, or in Chinese, 梁爽. $\mathrm{He}$ is the beneficiary of the love and cultural richness of two nations. He speaks to his mother and grandparents in Cantonese, and to us in English. He is a living bridge, as his name implies, and a source of hope and joy for us all.

I also found myself part of a group of scientists and leaders in education who were recognising an ever-greater need for high-level exchange as technologies rapidly advanced and our common problems revealed their urgency and complexity.

\section{Global Problems Require Global Solutions}

As a Fellow of the Royal Society in the UK, my colleagues and I met with our scientific peers from the Chinese Academy of Sciences. While our political leaders addressed issues of ideology, our focus remained on the pursuit of knowledge and its power to benefit the peoples of both our countries.

A number of Royal Society Fellows-members of the world's oldest independent scientific academy, dedicated to promoting excellence in science-have worked for decades with colleagues in China, particularly in areas such as medicine. While we spoke the common language of Science, the different cultural contexts in which we undertook our work revealed questions and insights which challenged each of us to think more carefully.

As Chair of the Nuffield Foundation - an independent charitable trust with a mission to advance educational opportunity and social well-being-I also discovered ways in which it was vital we work together. 
One established example of this was the globally respected Nuffield Council on Bioethics. The Council informs policy and public debate through timely consideration of the ethical questions raised by biological and medical research. Established by the Trustees of the Nuffield Foundation in 1991, it seeks to provide independent and balanced advice to policy-makers and stimulating debate in bioethics. Recommendations are backed by a thorough process of consultation, engagement and deliberation with a wide range of people and organisations. The Council's work is informed by engaging a range of public, professional, political and policy stakeholders to ensure that the Council is aware of, and responsive to, the major issues of interest and concern to them. And, it draws on a broad range of expertise and opinion to develop a range of high-quality outputs and activities, supported in this endeavour by the charitable research funder Wellcome and the UK Medical Research Council.

Yet, this vital work would clearly be incomplete if it did not draw on international insights and experience. The ethical underpinnings of biosciences and medicine have very practical consequences. So, the Nuffield Council on Bioethics had for example published collaborative research on the scientific and ethical aspects of ageing. There are currently more than 220 million elderly people in China. By 2050, more than $40 \%$ of the population will be over the age of 60 . Although Chinese governmental expenditures on healthcare and eldercare have been growing, the challenge of how to support an ageing population is as familiar in the East as it is in the West. What factors should we consider as we address this challenge?

And in China there are distinct challenges. The common '4-2-1' family structure of four grandparents, two parents and one child make eldercare in China one of the most pressing social issues of the time. The traditional Confucian value of "filial piety' and concerns about dignity and agency for older people in their own care touch on everything from inter-generational attitudes to medicines and housing - an issue also at the heart of policy concern in the UK. A process of urbanisation and changing patterns of employment meant many older people now lived far away from a generation who would have traditionally offered support. Seeking an understanding of a balance between cure and care led to deep academic collaboration between the Nuffield Council of Bioethics and the Xiamen University.

And it is not just medicine. New technologies present new ethical challenges, and it has become clear in recent years that the world is in urgent need of a common ethical framework for artificial intelligence. Yet, how to balance a western focus on individual freedom with eastern philosophical focus on the collective? Only by speaking together could we reveal our assumptions and question our thinking.

I took advice on this work from my academic colleague at The University of Cambridge, Professor Huw Price, who is a Bertrand Russell Professor of Philosophy and Academic Director of the Leverhulme Centre for the Future of Intelligence. Together with Professor Yi Zeng of the Chinese Academy of Sciences, Huw directs the China-UK Research Centre for AI Ethics and Governance, a cross-cultural and trans-disciplinary Centre. Through linking Eastern and Western wisdom, the Centre is aimed at bridging scholarship in China and the UK to share, interact and complement efforts about AI Ethics and Governance, with an aim of putting AI development at the service of humanity and social good. So, we convened honest discussions between 
leading Chinese and British philosophers to open up our thinking to one another, realising in the process that we would need to work hard not to misunderstand one another.

This work is long-term in nature, and that is its strength. The Nuffield Council for Bioethics has been seeking understanding and offering expert advice for 20 years. It is motivated by rigour and insight, not headlines. The ethical questions raised by caring for an ageing population or, of the beneficial societal uses of artificial intelligence, are likely to concern policy-makers and wider society for a generation to come. But without a thoughtful analysis of the issues involved in a truly global context, the opportunity for misunderstanding and inadvertent damage is clear. It was clear to the founders of the Nuffield Council on Bioethics that common purpose required greater understanding not only of technologies but of the cultural priorities and assumptions which guide their use. This meant being willing to challenge ourselves in the interests of the many millions of people who will feel the consequences of the decisions we make, whether in the UK or China.

\section{The Need for Mutual Understanding}

A great English author, sadly lost to us in 2020, John Le Carré, once wrote that: 'Learning a language is an act of friendship'. He was right. A language is much more than a currency that allows us to exchange thoughts and ideas. A language carries within it the stories and culture of a people.

To know another people, you must understand their fears and hopes, and often those are wrapped up in their language. It is how we recognise one another's common humanity, our hopes and dreams for the future. And understanding these is a precondition for peace.

The philosopher Ludwig Wittgenstein wrote, 'The limits of my language mean the limits of my world', and this is as true for those of us who explore the Sciences and the Arts. Sometimes, the challenges we face will require an interdisciplinary approach, while others an international one that draws on the experiences of our different cultures and traditions. It is by meeting one another, virtually and in person, that we expand our vocabulary and with it our comprehension.

For Science, a failure to meet and work together could carry a heavy price in misunderstanding. Certainly, the developing world must have its input into the solutions to the great social and ecological challenges of global health and climate change, and here, China speaks with authority. China has lifted 800 million people out of poverty and a significant portion of our global progress on this issue is due to this fact. How was this possible? On this, as so much else, I know my country has a lot to learn from my Chinese colleagues. 


\section{The Global Challenge of COVID-19}

The need to work together as a global scientific community has perhaps never been as starkly apparent as in response to the devastating pandemic of COVID-19. At the end of my road in Oxford are the laboratories of the University's Medical Division and the Jenner Institute where teams of scientists from around the world developed the Oxford Astra Zeneca vaccine, which has recently been approved in the UK and will be made available on a not-for-profit basis for the duration of the pandemic across the world, and in perpetuity to low- and middle-income countries. This scientific triumph will potentially save millions of lives, and give us back so many of the freedoms that have been curtailed during this pandemic.

Oxford University is, in fact, home to many scientists from China, both students and leaders in research. A few weeks ago, I shared a cup of tea in my garden in Oxford with a colleague and friend, Professor Zhanfeng Cui. At our socially distanced, but scientifically warm, meeting we talked about his Oxford Laboratory which is also just around the corner from my home.

Professor Cui is a distinguished Biomedical Engineer with a track record of bringing cutting-edge science to bear on important medical issues. Professor Cui is the Founding Director of Oxford's research laboratory in Suzhou. The institute, named OSCAR, will bring the combined expertise of Chinese and British scientists to solve problems of joint and global significance.

A recent example of the importance of such a joint lab is the development of techniques needed to fight the pandemic. He and his international team are working on COVID-19 detection in a joint project with scientists and medics from across the world. As we discussed the personal and the global, we were each keenly aware of the importance of his work for our own health, for our loved ones and all our neighbours and fellow citizens in China, the UK and the world.

\section{Learning from Scientific Colleagues in China}

On the wall of my office in Oxford are two framed prints, personal gifts from one of my brothers-in-Science Professor Xu. He is a Professor of the Academy of Arts and Design at Tsinghua University in Beijing China and Director of the Future Lab. His teaching and research focus on user experience in computer design and eheritage. Before joining Tsinghua University, he was a Lead Researcher for Microsoft Research in Asia. But the pictures remind me of his deep love for Chinese culture and our common humanity.

The images he gave me are of his digitisation for conservation purposes of ancient Buddhist cave paintings from Dunhuang in China which is an artistic and cultural wonder of the world. Yet, I also think of the very modern and universal applications of his work. 
Deeply committed to accessibility, Professor Xu and his Beijing team have also developed a prototype tactile display system that allows blind people to handle visual information from computers, hoping they can benefit more from the Internet age of booming graphic information. Named 'Graille', the display is comprised of a pinmatrix with 7,200 small tactile dots that can be raised and retracted. The computer controls the pin-matrix of the display to show graphic information in raised tactile dots, which can be read by touch by the blind users.

The idea started in 2009 when Professor $\mathrm{Xu}$, an expert in computer vision and interaction design, was working on a digitalisation project for cultural heritage. He noticed that blind visitors can only absorb information through voice introduction converted from texts. The lack of visual information makes it hard for them to appreciate museum exhibits. Professor Xu's team also worked with the Beijing School for the Blind to learn more about blind people's needs when handling visual information. The team is cooperating with major Internet companies to benefit blind users across China and the world.

\section{Building Understanding Is Personal}

These are just two personal examples of Chinese colleagues whose work I deeply admire, but I cite them for a reason. When we speak of the need for the UK and China to come together for our mutual benefit, we certainly need to consider the economic and institutional frameworks that will make this possible, but we should not forget the personal.

When I think of Chinese scholars and students, scientists and thinkers, I see individual faces and hear their stories. I do not think in terms of stereotypes but of people, colleagues and in many cases friends with whom I can work and think. As my school motto put it: 'He who would be a leader must be a bridge'. In my experience, facilitating bonds between countries begins by facilitating connections between people, it is personal.

When we speak on the phone, Professor Xu and I share stories of our grandchildren and hope that our work might in some way enhance their lives and worlds. Recently I told him: 'I hope for my family and yours that, whether the challenge is COVID-19 or climate change, we will continue to meet one another in a spirit of friendship and that our world will not be constrained by misunderstanding.' I believe it is our duty to work together to ensure that this is so.

Sir Keith Burnett is Chair of the Academic Council for Schmidt Science Fellows at Oxford University. He was President of the UK Science Council between 2016 and 2021 and is Chairman of the Nuffield Foundation, a charity which funds research, analysis and student programmes. He is also well-known as an advocate for international students and is widely published in the UK and globally. Sir Keith retired as President and Vice-Chancellor of the University of Sheffield in 2018. He took on the position in 2007 and before he was Head of the Division of Mathematical, Physical and Life Sciences at the University of Oxford. 
Open Access This chapter is licensed under the terms of the Creative Commons AttributionNonCommercial-NoDerivatives 4.0 International License (http://creativecommons.org/licenses/bync-nd/4.0/), which permits any noncommercial use, sharing, distribution and reproduction in any medium or format, as long as you give appropriate credit to the original author(s) and the source, provide a link to the Creative Commons license and indicate if you modified the licensed material. You do not have permission under this license to share adapted material derived from this chapter or parts of it.

The images or other third party material in this chapter are included in the chapter's Creative Commons license, unless indicated otherwise in a credit line to the material. If material is not included in the chapter's Creative Commons license and your intended use is not permitted by statutory regulation or exceeds the permitted use, you will need to obtain permission directly from the copyright holder.

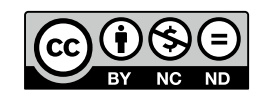

